\title{
DO SINGULAR AO SINGULAR: FINITUDE, TRANS-HISTORICIDADE E COMPREENSÃO EM SARTRE
}

\author{
Marcelo Prates ${ }^{1}$ \\ Universidade Estadual do Centro-Oeste (UNICENTRO) \\ (D) https://orcid.org/0000-0001-5180-6053 \\ E-mail:marceloprates1@gmail.com
}

\section{RESUMO:}

Este artigo tem por objetivo analisar na filosofia de Sartre a relação entre as subjetividades a partir da noção de compreensão. Diferenciando conhecimento de compreensão, Sartre propõe que pela compreensão seja possível apreender a subjetividade sem torná-la um saber objetivo. Embora aponte isso em vários de seus estudos é na conferência sobre Kierkegaard que tal tese se torna mais manifesta. Neste artigo procuramos demonstrar que essa tese modifica toda uma percepção sobre a liberdade, de modo que ela enquanto singularidade possui uma dimensão trans-histórica, ao mesmo passo em que só pode ser tomada, em sua finitude própria, pela compreensão. Tal tese não contraria as da ontologia, mas, justamente, legitima nela o Ser como finitude. Por fim, a liberdade não é denotada como um saber objetivo, mas como um convite à compreensão de nós mesmos.

PAlAVRAS-CHAVE: Ontologia; Fenomenologia; Dialética; Liberdade; Finitude.

\section{FROM SINGULAR TO SINGULAR: FINITUDE, TRANSHISTORICITY AND UNDERSTANDING IN SARTRE}

\begin{abstract}
:
This article aims to analyze in Sartre's philosophy the relation between the subjectivities from the notion of understanding. Differentiating knowledge of understanding, Sartre proposes that by understanding it is possible to apprehend subjectivity without making it an objective knowledge. Although he points this in several of his studies is the conference on Kierkegaard that this thesis becomes more manifest. In this article we try to demonstrate that this thesis modifies a whole perception about the freedom, so that it as a singularity has a transhistorical dimension, at the same time that it can only be taken, in its own finitude, by understanding. This thesis does not contradict those of the ontology, but, rightly, legitimates the Being as finitude. Finally, freedom is not denoted as an objective knowledge, but as an invitation to understanding ourselves.
\end{abstract}

KEYWORDS: Ontology; Phenomenology; Dialectic; Freedom; Finitude.

\footnotetext{
${ }^{1}$ Doutor(a) em Filosofia pela Universidade Federal do Paraná (UFPR), Curitiba - PR, Brasil. Professor(a) colaborador(a) na Universidade Estadual do Centro-Oeste (UNICENTRO), Guarapuava - PR, Brasil.

PRATES, Marcelo. Do singular ao singular: finitude, trans-historicidade e compreensão em Sartre. (1817). Griot : Revista de Filosofia, Amargosa - BA, v.21 n.3, p.268-282, outubro, 2021.
} 
A filosofia de Sartre é uma filosofia da liberdade. Também é reconhecida como uma filosofia da subjetividade, do indivíduo, da consciência. Desde $O$ ser e o nada, com ênfase nos Cadernos para um moral, Sartre passa a enfatizar a liberdade em seu aspecto de criação de si mesmo (SARTRE, 1983, p. 134, 135). Naquele momento de seu pensamento, posto que é um escrito póstumo, a criação denota a liberdade em seu ato e prolongamento de existência como doação de ser. "Doar, essa é a verdadeira palavra" (SARTRE, 1983, p. 157), pois "a criação é também processo de doação" (SARTRE, 1983, p. 135). A partir desse mote, a criação de si passará a ser tomada concomitantemente como criação do mundo. Por isso Sartre aponta que essa condição é também uma forma de "comunicação de ser", pois "só podemos doar o que temos" (SARTRE, 1983, p. 157), de tal modo que "Criamo-nos a nós mesmos se doando ao outro" (SARTRE, 1983, p. 136). Essa condição aponta primeiramente às formas de relação com o outro que, doravante, podem ser pensadas não apenas de acordo com o conflito ontológico, mas segundo a lógica da generosidade: "a generosidade absoluta e sem limites, como paixão propriamente dita e como único meio de ser. Não há outra razão de ser que se doar. E não é apenas a obra que é doação. O personagem (caractère) é doação. O Eu (Moi) é a rubrica unificadora de nossa generosidade" (SARTRE, 1983, p. 137).

O que pretendemos salientar é que essa doação não aparece apenas como marca da objetividade do mundo para além da consciência nadificante ou da possibilidade de relação para além da ideia de conflito, mas o seu aspecto epistemológico solidificado na pessoa que se doa e se cria no mesmo ato e, portanto, não pode distinguir essa doação da doação de seu ser inteiro. Em outras palavras, a doação enquanto criação do mundo implica uma criação de si e uma doação de si no mesmo ato, inteiramente. Ora, é sobre esse escopo que Sartre assenta a ideia de compreensão, a qual será ratificada posteriormente na dialética da Crítica. Nesta obra Sartre pensará a compreensão como "simplesmente o movimento dialético que explica o ato pela sua significação terminal a partir de suas condições de partida" (SARTRE, 2002a, p. 115), posição essa que segue a linha da psicanálise existencial, a qual tem como princípio a compreensão de nosso ser em sua totalidade, portanto, da nossa liberdade factiamente construída temporalmente. Mas é na conferência sobre Kierkegaard que encontramos mais bem explicitada essa relação da criação, doação e compreensão. Ali Sartre tomará a compreensão como uma forma de conhecimento do subjetivo, na medida em que o outro ao se compreender e se doar, se dá a compreender, para além de toda tomada objetiva que posso ter sobre seu ser, a qual reduziria seu ser ao conhecimento objetivo que teríamos dele.

Por isso a compreensão ao apelar à totalidade do existente e, por isso mesmo, a sua liberdade e criação, possibilitaria não apenas a compreensão de mim mesmo, mas também do outro em sua liberdade, isto é, em seu aspecto também subjetivo. Isso é importante porque uma vez que as relações estão fadadas à objetivação, à tomada da liberdade do outro a partir do meu olhar objetivador, portanto, tomando-o como objeto e não como sujeito, este solo da compreensão possibilitaria, assim, a tomada do outro em sua subjetividade, em sua liberdade. $O$ objetivo de nosso texto é analisar essa proposta de Sartre da compreensão como modo de conhecimento do subjetivo pelo subjetivo, pensando não a imagem de uma subjetividade pura à outra subjetividade pura (de uma consciência transcendental à outra), mas da liberdade concreta e, portanto, de uma singularidade à outra singularidade. Veremos que com isso é possível uma apreensão do sujeito histórico para além do saber objetivo, pois a compreensão é uma tomada do subjetivo ao subjetivo. Assim sendo, a própria imagem do humano e da liberdade é corroborada na ideia de generosidade pela forma da compreensão e, por ela, uma nova forma de pensar a finitude e a liberdade humana. Ademais, "ou a História se fecha num conhecimento morto ou a sobrevivência histórica do subjetivo deve mudar nossa concepção de História" (SARTRE, 1972, p. 154). 
A conferência é bastante curiosa, pois para uma filosofia da finitude radical, perguntar pelo que resta depois da morte, para além da tomada objetiva, como em-si, parece ser uma questão sem fundamento. Ora, por isso aparece como um escândalo e um paradoxo do "aparecimento e do desaparecimento deste absoluto no tempo da História" (SARTRE, 1972, p. 153). Pensando não tanto o fator de universalidade e individualidade, mas como pode o subjetivo se resguardar do fator da morte sem cair absolutamente como objeto ou como dependente da subjetividade do outro, Sartre procura mostrar como Kierkegaard enquanto sujeito que viveu sua época, transcende-a não apenas enquanto objeto de conhecimento, mas também enquanto subjetividade para além da própria morte. Não sendo, assim, memória pessoal de um outro, referência morta e genérica da cultura, signo objetivo e estático, Sartre explicita a compreensão e pela compreensão como Kierkegaard permanece enquanto sujeito absoluto e, portanto, trans-histórico na História.

Em razão disso, não se trata de recolocar o problema metafísico da morte, problema que $O$ ser e o nada já respondia, mas sua problematização ante à história. Trata-se, antes, do "paradoxo estritamente histórico da sobrevivência" (SARTRE, 1972, p. 153), mas sobrevivência da subjetividade. E isso deveria nos modificar sobretudo a concepção de História como movimento totalizante que anula o subjetivo e o reduz ao saber objetivo e inerte da cultura, concepção que Sartre não aceitará pelo fato de que ela faria da liberdade apenas um momento do Espírito Objetivo, mas jamais o seu fundamento. Assim, podermos ver que a dialética entre o subjetivo e o objetivo não é somente de negação ou aniquilação de um dos termos, mas, e é isso que queremos demonstrar com esse artigo, ela implica uma outra dialética, do subjetivo ao subjetivo. Dialética para a qual não haverá suprassunção, mas diferenciação, cujo processo instaura a finitude e possibilita a tomada da finitude não mais pelo processo do Espirito Objetivo, mas por ela mesma. Com isso a filosofia de Sartre se ratifica como uma filosofia que toma a finitude em sua radicalidade e como fundamento não metafísico do real enquanto contingência. Ademais, é somente a partir dessa dialética do singular para o singular que Sartre poderá defender sua tese de que "a posteridade e a contemporaneidade se implicam mutuamente e se contradizem" (SARTRE, 1972, p. 154), de modo que a tese da compreensão afirma a da contemporaneidade entre os sujeitos - "nós somos todos contemporâneos" (SARTRE, 1972, p.154) -, mas sem os diluir numa homogeneidade e, portanto, resguardando-os em sua finitude. Como bem aponta Bornheim,

A crise da metafísica apresenta um sentido basicamente positivo. Positivo no caso quer dizer: abertura para a finitude, para uma compreensão finita do ser finito. E convém acrescentar que o pensamento da finitude é antes de tudo pensamento da diferença. No contexto da Metafísica não existe pensamento da diferença; A Metafísica deve ser caracterizada como vontade de abolir a separação, de suspender, portanto, a diferença: A Metafísica persegue a redutibilidade do outro ao mesmo, e deságua por essa razão no monismo (BORNHEIM, 1983, p. 80).

É por esta vereda que analisaremos a conferência. Em seu mote, a conferência Kierkegaard vivo, estando ele morto, coloca a questão de como um sujeito que não está mais vivo pode dar-se não a conhecer, mas a compreender, isto é, como pode ele ainda fazer sua subjetividade escorrer na história, ser trans-histórica. Ela trata, assim, da "trans-historicidade do homem histórico" (SARTRE, 1972, p. 154). De fato, Kierkegaard se perde na história, pois "para o saber histórico se vive para morrer" (SARTRE, 1972, p. 164), isto é, a existência singular se dissolve na homogeneidade do conceito, do signo estático. Por certo, não há como nenhuma nova vida reproduzir Kierkegaard sob uma forma de ressureição. Tudo o que resta de Kierkegaard são seus escritos, feitos em outros tempos, com outros meios, e que só pode responder "parcialmente nossas exigências presentes". Ora, em que e como Kierkegaard pode restituir um presente muito posterior 
ao seu, com uma profundidade que advém não tão somente com sua obra, mas também com sua subjetividade?

Tanto em $O$ ser e o nada quanto na conferência sobre Kierkegaard Sartre afirma que são os outros que reavivam tais escritos. Em $O$ ser e o nada Sartre já aponta, mesmo sem reportar a uma obra feita por uma vida, que o passado desta vida não é igualmente extinto quando ela deixa de viver. Se o homem é transcendência e facticidade, em-si e para-si, ipseidade e ser-no-mundo, com a morte ele submerge no em-si, o que significa que ele já "não pode modificar-se pela simples consciência que tem de si mesmo. Muito pelo contrário, o sentido de um fenômeno qualquer desta vida fica determinado daqui por diante, não por ele mesmo, mas pela totalidade aberta que é a vida interrompida" (SARTRE, 2007, p. 585). Com isso tal qualidade que é a vida de um indivíduo não para de se transformar, porém não mais pelo próprio indivíduo, mas pelas alterações exteriores que o mundo lhe impõe: "a vida morta tampouco cessa de mudar por ser morta, mas não se faz: é feita."( SARTRE, 2007, p. 588). Assim, ela continua sendo alterada, mas agora pelo outro que, sendo o "guardião da sua finitude" (SARTRE, 1983, p. 523), segura na condição cultural toda a memória para impedir que se "atrofie até sua plenitude do Em-si, rompendo todas as suas amarras com o presente" (SARTRE, 2007, p. 586). Nesse sentido, a memória social e o esquecimento são condições mais práticas e concretas que ontológicas. Isso porque Sartre pensa o esquecimento não somente como um apagamento total na opacidade do ser, mas sobretudo como massificação histórica e perda absoluta da subjetividade ${ }^{2} \mathrm{em}$ sua irredutibilidade. Tudo se passa como se o indivíduo fosse a raiz do singular universal, cuja cultura o arrasta historicamente, mas que a perda da subjetividade pela morte, a perda daquela singularidade que foi capaz de mudar de maneira única o universal e agora entregue à cultura, aos outros, fizesse o indivíduo sucumbir, assim, ao saber histórico objetivo, mas sobretudo por sua massificação e, portanto, sua diluição no prático-inerte. Assim, mesmo que se atribuísse ao outro a guarda da memória e do sujeito, ela não escaparia à determinação como prático-inerte.

Por isso a morte não se torna um fator de finitude, ela demarca uma contingência e não uma estrutura da consciência, diferente da finitude que é considerada uma estrutura ontológica do para-si que o determina como liberdade. Sartre associa o ato de liberdade ao ato de "criação da finitude" (SARTRE, 2007, p. 591). Sendo livre e finito, o homem se singulariza enquanto escolha de ser e criação de si como maneira de ser. Processo esse que implica toda a temporalidade de sua existência em seu conjunto de acontecimentos e situação, mesmo para uma curta existência. Com isso o tempo se torna a condição de singularização na medida em que toda singularização é o processo de ser. Assim sendo, "se eu me faço, faço-me finito e, por esse fato, minha vida é única" (SARTRE, 2007, p. 591). Portanto, é por ser finitude que a subjetividade se cria e se faz enquanto singularidade e não porque é para-a-morte. A questão é justamente esse processo e o que dele permanece não como saber objetivo, mas como subjetividade:

Como fundar a validez trans-histórica de um pensamento que se produz na história e que nela desaparece? A resposta está na "reduplicação": o insuperável não pode ser o saber, senão a instauração na história de uma relação absoluta e não contemplativa com o absoluto que se realizou na história. Ao invés de o saber dissolver o pensador, é ele que dá testemunho de seu próprio pensamento (SARTRE, 1972, p. 169).

Fazer de Kierkegaard apenas objeto de conhecimento seria reduzir a interioridade à exterioridade, seria tomar a singularidade por sua universalidade, cujo mote é resguardado na

\footnotetext{
${ }^{2}$ Segundo ele, "Ser esquecido é ser objeto de uma atitude do outro e de uma decisão implícita do Outro. Com efeito, ser esquecido é ser aprendido resolutamente e para sempre como elemento dissolvido em uma massa (os "grandes senhores feudais do século XIII", os "burgueses Whigs do século XVIII", os "funcionários soviéticos", etc.); não é de forma alguma nulificar-se, mas perder a existência pessoal para ser constituído como outros em existência coletiva (SARTRE, 2007, p. 586)
}

PRATES, Marcelo. Do singular ao singular: finitude, trans-historicidade e compreensão em Sartre. (1817). Griot : Revista de Filosofia, Amargosa - BA, v.21 n.3, p.268-282, outubro, 2021 
matéria e na cultura como destino social. Isso seria destituir a própria realidade do singular perante o universal e confirmar a tese de que, "para o saber histórico, vivemos para morrer" (SARTRE, 1972, p. 164), pois o indivíduo deve desaparecer e ser suplantando pelo conceito. Não por menos, "todo empreendimento vivido resulta em fracasso pela simples razão que a História continua" (SARTRE, 1972, p. 164). Dessa continuidade do mundo resulta a predominância do conhecimento sobre o indivíduo. Mas a tese de Sartre é que o conhecimento do universal é distinto pela sua homogeneização, massificação, serialização, repetição, passividade própria do práticoinerte como antidialética. Aceitar a coagulação de Kierkegaard na História seria aceitar a morte do subjetivo e a vitória do prático-inerte.

Mas, para Sartre o universal não é senão a singularidade da vivência histórica, de modo que a própria instituição "é a singularidade tornada lei para os outros e para mim" (SARTRE, 1972, p. 179). O que Sartre pretende é mostrar como a singularidade se esquiva ao destino do universal ao mesmo tempo em que é tomada por uma outra forma de apreensão. Kierkegaard aparece como objeto privilegiado porque explicita bem esse conflito entre ser e existência, nãosaber e saber na História, pelo fato de que ele formula "o problema por sua própria vida" (SARTRE, 1972, p. 163), isto é, não se deixa reduzir ao universal. Ora, não se trata de uma simples negação do universal, mas de que, "a revolução é que o homem histórico, por sua ancoragem, faz dessa universalidade uma situação particular e da necessidade comum uma contingência irredutível" (SARTRE, 1972, p. 173). É nesse ponto que a subjetividade se torna o absoluto, absoluto de existência, ser que só pode tomando na finitude. Isso porque o particular não é uma encarnação dialética do universal, ao contrário, é "a ancoragem da pessoa que faz desse universal uma singularidade irredutível" (SARTRE, 1972, p. 173.). Assim, a ancoragem, inversamente, antes de ser uma determinação, é a maneira como essa pessoa vive e, por isso mesmo, escapa ao destino social e à imposição do prático-inerte por sua singularidade:

Aquilo que nenhum progresso histórico pode recuperar: o fracasso vivido no desespero: os mortos de angústia, de fome, de exaustão, os derrotados pelas armas são falhas no saber pelo modo como existiram. A subjetividade não é nada para o saber objetivo, pois ela é não-saber e, no entanto, o fracasso mostra que ela existe absolutamente (SARTRE, 1972, p. 166, negrito meu).

Ora, porque esta verdade não pode ser diluída no conhecimento objetivo, ao menos depois da morte? Sartre, se referindo às Migalhas filosóficas, aponta que essa não-verdade ele só pode descobri-la sozinho (SARTRE, 1972, p. 157), e é nessa condição que ela escapa ao saber. Aqui a solidão é a irredutibilidade com que ela é vivida. Observe-se que não é que um ato não possa se transformar num fato ou valor social e mesmo ser selado pela matéria como signo. Mas o que está em questão é que o fato da objetivação deste fenômeno, o saber objetivo da guerra, da fome, não se reduz as suas vivências subjetivas. Ao generalizar perde-se toda a força de acontecimento vivo e, portanto, de como ele foi vivido. Daí que discursos sobre a guerra e a fome possam chegar a ser meras palavras ao vento e em nada nos levar ao conhecimento vivo de nós mesmos, bem como trair a própria vivência a ponto de destituí-la de todo seu peso e força histórica. Pelo saber objetivo tomamos a forma como dada, como valor estático, como vivência irredutível. Ela aponta ao fato, mas não à condição do fato, isto é, à liberdade. E será por este motivo que

minha não-verdade descoberta se torna, ao menos no imediato, minha verdade. Então a verdade subjetiva existe. Ela não é saber, mas autodeterminação; ela não será definida nem como uma relação extrínseca do conhecimento ao ser, nem como a marca interna de uma adequação, nem como a indissolúvel unidade de um sistema. 'A verdade, diz ele, é o ato da liberdade" (SARTRE, 1972, p. 158, negrito meu). 
É essa irrupção de uma determinação cuja condição aponta a uma irredutíbilidade e que é a causa da mudança, naquilo que é vivido, que provoca a transformação na História. Essa vivência escapa ao saber porque, seguindo Heidegger, nela o agente é "questão em seu ser, na medida em que ele não é senão sob o modo de ter de ser seu ser" (SARTRE, 1972, p. 159). Ora, porque essa vivência escapa ao universal ao mesmo tempo que o vive? Pelo fato de que ela coloca em questão seu ser ao apontar sua a inadequação à situação: "O questionador é posto em questão em seu ser pelo questionado" (SARTRE, 1972, p. 167). É esse acontecimento que escapa à história, dado que "Cada um de nós, em sua própria historicidade, escapa à História na medida mesma em que a faz" (SARTRE, 1972, p. 179). Fazer a História ao mesmo tempo em que se escapa a ela é colocar a liberdade como sua condição, liberdade que, justamente por ser condição, não pode se reduzir ao condicionado, à facticidade. Mas não por sua abrangência de princípio, como seria o nada tomado abstratamente, mas justamente por sua irredutibilidade, isto é, por sua finitude. Por isso a verdade subjetiva é um "absoluto temporalizado", temporalizado porque pertence a uma situação e se faz nela para além dela, e absoluto porque não se reduz às determinações históricas, nem mesmo na sua tomada objetivante e universalizante, mas se configura justamente como seu ultrapassamento. Por isso ela é temporalizada porque se temporaliza, e isso implica, ao ser questão para si mesmo, fazer com que seu tempo, o da vivência, não coincida necessariamente com a determinação da história: "A subjetividade é a própria temporalização; é o que me acontece, o que não pode ser senão me acontecendo; é eu na medida em que só posso nascer em uma aventura" (SARTRE, 1972, p. 159). Pois, se o subjetivo é "uma realização singular de cada singularidade" (SARTRE, 1972, p. 158), isso torna o acontecimento que sou, enquanto questão para mim mesmo e de meu tempo, um irredutível, de modo que "essa negação do saber implica a afirmação de si mesmo" (SARTRE, 1972, p. 159), sua autodeterminação; sendo, assim, assunção de sua finitude e singularidade como motor da História sem reduzir-se a ela. Daí que um estudo da História pela liberdade exija que se transcenda do fato à liberdade, movimento este que só pode ser dado pela compreensão enquanto tomada do subjetivo pelo subjetivo.

Isso quer dizer que não apenas a obra de Kierkegaard mostra esse apontamento ao indivíduo, mas que sua vida, para além dessa determinação, transmite essa qualidade, essa maneira como ele coloca em questão seu tempo e se eleva como absoluto temporalizado e transhistórico. Por isso que Sartre enfatiza a todo momento que não são os escritos, mas a própria subjetividade viva de Kierkegaard que ele aponta:

Vivo, Kierkegaard vive o paradoxo na paixão: apaixonadamente ele quer se designar como um absoluto trans-histórico; pelo humor, pela ironia, ele se mostra e se esconde ao mesmo tempo. Não é verdade que ele recusa se comunicar; simplesmente ele permanece em segredo na própria comunicação. Sua mania de pseudônimos é uma desqualificação sistemática do nome próprio" (SARTRE, 1972, p. 161, negrito meu).

É essa ambiguidade que em Kierkegaard salta aos olhos, pois esses aspectos subjetivos não são apenas elementos secundários, mas a condição, a maneira de ser de Kierkegaard, de modo que sua obra, antes de ser um monumento objetivo, é um labirinto da subjetividade, de modo tal que quando pensamos encontrar a saída ao objetivo, damos às voltas com as paredes da subjetividade. Todo esse movimento não é outro que a singularidade de Kierkegaard. Por ela Sartre mostra não o nada nadificador como condição geral, nem a História como destino absoluto, mas a maneira como que essa subjetividade escapa ao saber objetivo. Por isso podemos, em qualquer obra ou vida de qualquer pessoa, tanto apreendê-la de maneira objetiva quanto buscar seu salto qualitativo, sua singularidade, como Sartre faz em seus estudos biográficos. Kierkegaard aparece como um objeto privilegiado porque ele quer escapar ao saber, sua obra se apresenta como uma 
luta contra a objetivação. A singularidade é o ponto chave da subjetividade porque aponta não a individualidade, mas a maneira como ele a faz. É isso que é resguardado da morte e possibilita uma certa imortalidade, a qual não é somente objeto de saber, mas "uma certa relação absoluta da imanência à transcendência, que não se pode estabelecer, senão no vivido e pelo vivido" (SARTRE, 1972, p. 168). Sendo, então, uma relação assentada na vivência, o ponto de partida desse trans-histórico que é Kierkegaard, sua pessoa, mesmo sendo um não-saber, é uma relação inserida na História e traz toda sua composição a partir dessa nova orientação que é ao mesmo tempo desvio e apropriação.

Ora, tal apropriação enquanto constituição e formação, sendo ela uma relação vivida, aponta toda a subjetividade, pois a singularização é a vida levada ao seu termo na finitude. Nesse sentido, ela engloba essa liberdade desde seus primórdios em seu nascimento, tomando mesmo essa fase passiva e obscura de interiorização que é a infância também como criadora e constitutiva da liberdade. Com isso há toda uma composição na história pela singularidade, cujo começo se dá conforme a situação como ele nasce, ocorrendo já nesse nascimento tal mudança segundo a personalidade enquanto processo temporal pelo fato de que nesse processo a universalidade é convertida numa situação particular e a necessidade histórica numa contingência irredutível.

A contingência pela singularidade implica a dialética do indivíduo com o prático-inerte, pois é contingente e gratuita essa nova subjetividade e, no entanto, é ela que reconfigura todo o campo já solidificado na necessidade histórica a partir da facticidade histórica. Aqui a contingência faz da necessidade puro aglomerado histórico de acasos, cuja exterioridade de indiferença é seu fundo, mas que enquanto enraizado na pessoa converte este universal histórico em uma "singularidade irredutível" (SARTRE, 1972, p. 173). Essas condições que escapam a todo racionalismo hegeliano, justamente por se tratar de uma contingência pura, demarca que sendo o ser sem razão, cada acontecimento mínimo implica toda essa composição única, como no caso de Kierkegaard: "A origem da singularidade é o acaso mais radical: se eu tivesse um outro pai... Se meu pai não tivesse blasfemado, etc." (SARTRE, 1972, p. 174).

Se torna radical porque imprescindível à tal personalidade, onde cada escolha, cada objeto fáctico adquire seu grau de importância ante tal personalidade, que vai desde a presença de uma pessoa à forma mais básica interiorizada nos primeiros anos, como o viscoso tão salientado por Sartre. Nesse sentido é que "esse acaso pré-natal volta a encontrar-se na pessoa mesma em suas determinações" (SARTRE, 1972, p. 174). Mas sendo uma contingência, fruto do acaso ou da exterioridade de indiferença do ser, Sartre assume esse "acaso singularizador" (SARTRE, 1972, p. 174) não num tom metafísico, mas eminentemente prático porque é toda a conjuntura material e não hipotética que faz de Kierkegaard a "anomalia" que ele foi. Nesse sentido, sendo uma composição de acasos na facticidade, toda parte de apropriação implica um enraizamento único e singular de toda conjuntura como "unidade desunida dos acasos que o produzem" (SARTRE, 1972, p. 177). Disso se segue que “a necessidade hegeliana não é negada, porém não pode encarnarse sem fazer-se contingência opaca e singular; em um indivíduo a razão da história é vivida irredutivelmente como loucura, acaso interior, que expressa encontros de acaso" (SARTRE, 1972, p. 174).

Do contrário, seria cair na teia da necessidade histórica. Por isso, no fundo, é a liberdade que decide e, por ela, será "a situação total que decide" (SARTRE, 2013, p. 56), rejeitando, assim, tanto um apriorismo histórico quanto psíquico. Deste modo, ao restituir a contingência e a liberdade do acontecimento, se aponta a predominância do acaso nas determinações da situação pelo fato de que é impossível estabelecer variáveis fixas, do contrário seria destituir a liberdade da sua condição de criação e irrupção absoluta na história e no ser. Por isso o objetivo de Sartre não é recuperar essas variáveis, mas a totalidade delas enquanto singularização na situação, tal como aponta no seu método psicanalítico existencial e biográfico: 
O que procuramos aqui, nós, é a criança de sorte, o encontro de certo corpo com certa mãe: laço não-compreensível visto que duas séries se encontram sem que possamos explicar o cruzamento; e, ao mesmo tempo, compreensão primeira, fundamento compreensível de toda compreensão: de fato, essas determinações elementares, longe de somarem ou afetarem uma à outra em aparência, são imediatamente inscritas no campo sintético de uma totalização [...] Por fím subimos o curso dessa vida até o seu começo: nós a interrogamos sobre o primeiro acaso ultrapassado, isto é, sobre a característica fundamental de seu destino (SARTRE, 2013, p. 59, negrito meu).

A irrupção da liberdade nesse conjunto de acasos como sua singularização e totalização, e esse movimento como sendo também ultrapassamento dessa situação, aferem à personalidade do indivíduo. Nesse processo, aponta-se não apenas à contingência fáctica e histórica, mas, concomitantemente, aos modos singulares com que se vive na época. Por isso Kierkegaard não é uma subjetividade perdida no meio da objetividade do mundo e dos outros, mas, nesse conjunto de acasos, encontra também outras singularidades. Não seriam, assim, duas dialéticas e uma a fundar a outra, mas dois processos concomitantes, do singular ao universal e do singular ao singular, não o encontro apenas do filho com o pai, mas de Kierkegaard com certo pai (SARTRE, 1972 , p. 174). Por isso que o processo de personalização em Sartre não é distinto do processo mesmo da liberdade, porquanto "só há absoluto histórico enraizado no acaso; pela necessidade de ancoragem, ele só é encarnação do universal na irredutível opacidade do singular" (SARTRE, 1972, p. 175). Por isso que desde esse acaso ocorre a criação ${ }^{3}$ e singularização, tal que "a síntese compreensiva só se encerra na morte" (SARTRE, 2013, p. 55). Assim sendo, não é a facticidade na exterioridade de indiferença, como puro acaso, que faz irromper a liberdade, mas a liberdade pelas liberdades na contingência fáctica da História. Logo, compreendemos que o irredutível como singularidade que emerge enquanto maneira de ser e que, portanto, dá a compreender sua singularidade, é também o resultado do seu processo de compreensão das liberdades de seu tempo, enquanto ultrapassamento de todo esse meio histórico:

viver a contingência original é ultrapassá-la: o homem, irremediável singularidade, é o ser pelo qual o universal vem ao mundo, e o acaso constitutivo, assim que vivido, toma a forma da necessidade. O vivido, nós aprendemos em Kierkegaard, são os acasos não significantes do ser na medida em que são ultrapassados rumo a um sentido que eles não tinham no começo e que eu nomeio de universal singular (SARTRE, 1972, p. 175)

E uma vez que esse acontecimento que é a irrupção na história é vivido, tal vivência implica em sua virulência o mínimo de ação própria dessa singularização desde seu início, é a necessidade da liberdade 4 . Por isso nenhuma vida surge senão pela liberdade, embora possa sucumbir ao

\footnotetext{
${ }^{3}$ Com relação a isso, para Sartre, "quando se trata da pessoa humana, o acaso é ele próprio produtor de sentido; o que quer dizer, em geral, que a existência assume a facticidade sem conseguir fundá-la e, em cada caso particular, que qualquer indivíduo deve poder-se manifestar-se como homem de acaso (insignificante) ou de um certo acaso (supersignificante); é o que Mallarmé nos explica em “Um lance de dados"... O lance de dados jamais abolirá o acaso, pois ele contém o acaso em sua essência prática” (SARTRE, 2013, p. 58).

4 "O vivido ocorre por uma irreprimível espontaneidade que a criança experimenta e produz sem ser sua fonte; mas ao mesmo tempo aparece como um engarrafamento de acasos que desfilam um por um sem que nenhum deles possa anunciar o seguinte ou explicar-se pelo precedente. É claro que a inteligência e a prática reconhecem no mundo circundante formas temporais - séries ordenadas, conjuntos unificados, totalidades que se totalizam, rigorosos encadeamentos de meios e fins; ensinam-lhe a procurar, a encontrar as premissas necessárias dos fatos que saltam sobre ele como ladrões ou que fogem por entre suas pernas, a ver neles, por mais inesperados que sejam, consequências; ele apreende sem esforço que nada existe sem uma razão. Mas sua confusão é aumentada ainda mais assim que ele se retrai em si mesmo, pois encontra uma existência sem razão de ser: a sua. Na base dessa exploração confusa ele descobrirá, talvez, muito mais tarde, uma verdade da Razão: pois a existência de um martelo e a existência de um homem não tem medida comum; o martelo está aqui para martelar, o homem não está "aqui", ele se lança no mundo; fonte de toda práxis, sua realidade profunda é a objetivação; isso quer dizer que a justificação desse "ser mais longínquo" é sempre 
prático-inerte. Daí que quanto maior a resistência e implosão, mais essa liberdade irradia para além do conhecimento histórico e se constitui, nessa superação, sua personalidade e liberdade na e contra a História. Deste modo, Sartre pensa que "viver a contingência original é superá-la" (SARTRE, 1972, p. 175) e é essa superação, o gosto que ela dá por sua resistência e criação, que não encontramos numa fórmula objetiva. Não basta dizer: viva o indivíduo! Viva a liberdade! É preciso fazer sentir essa irredutibilidade para além da codificação em signos. Ora, em Kierkegaard "sua obra nos reenvia, sem dizer, a sua vida" (SARTRE, 1972, p. 175).

Se a vida aponta à singularidade irredutível, ao subjetivo vivido e não a tomada objetiva desse, é pelo fato de que a autodeterminação, o momento da questão sobre seu ser e ultrapassamento dele, não pode vir a nós como uma fórmula, mas em sua recusa em "ser objeto de conhecimento e cuja originalidade reside precisamente nessa recusa; há aí um irredutível" (SARTRE, 1972, p. 155). Observe-se que, nesse caso, a liberdade pode ser descrita na forma de um conhecimento objetivo, uma determinação ontológica como é a ideia de nadificação, mas ela jamais se reduz a uma fórmula ou a uma tomada objetiva dela. Ela dá a compreender, seja a si mesmo, seja os outros, seja a si mesmo pelos outros. É nesse sentido que ela é enraizada historicamente ao mesmo tempo em que é trans-histórica, isto é, ultrapassa a objetividade fáctica e generalizante que se possa dar ao universalizá-la e institucionalizá-la. Por isso "Kierkegaard marca, por sua simples vida, que um saber concernente ao subjetivo é, de certo modo, um falso saber" (SARTRE, 1972, p. 156). E falso porque é impossível apreendê-lo como universal. Essa apreensão do indivíduo por sua liberdade sem ser objetivada ou universalizada é a tomada da sua singularidade e da sua diferença:

Ele é diferente de todos os outros, diferente de si mesmo, diferente do que ele escreve. Ele institui sua particularidade pela escolha livre de ser singular, isso quer dizer que ele se estabelece nesse momento ambíguo onde a interiorização, prenhe da exteriorização futura, se suprime para que aquela possa nascer (SARTRE, 1972, p. 184).

Assim, se sentimos a sua liberdade como questão também para nós, e isso é o que faz dele um vivo em nosso tempo, não é apenas porque ela aponta uma negatividade, mas também porque essa negatividade é ultrapassamento, e só pode sê-lo se fazendo singular. Daí que ela negue o ponto de vista intemporal, que remeteria ao ser, se fazendo temporalizada, embora em seu próprio ultrapassamento essa temporalização, por sua singularidade mesma, se faça trans-histórica. Eis o sentido do paradoxo de que a subjetividade se faz trans-histórica na História (SARTRE, 1972, p. 168). Portanto, é no vivido que se encontra o ponto de partida, pois ele abarca a totalidade que é a "pessoa" (SARTRE, 1972, p. 169) em sua liberdade, "visada como não-saber, isto é, enquanto ela produz e descobre, em um certo momento do curso temporal de sua vida, sua relação a ela mesma que é um absoluto que é ela mesma inserida na História" (SARTRE, 1972, p. 169).

Essa compreensão que é apontada da obra à vida sentimos na singularidade de sua obra, seja do uso que ele faz do mito, da ironia, do humor, para comunicar-se conosco indiretamente (SARTRE, 1972, p 182), seja em seus próprios conceitos que não se deixam captar na universalidade; e quando tentamos apreendê-los objetivamente ou sentimos uma generalidade que não lhe cabe, ou somos conduzidos a essa temporalização inquietante que nos leva não a procurar uma verdade, mas a tomar, por nossa conta, nossa própria questão em nosso ser. Por

\footnotetext{
retrospectiva: ela volta para ele do fundo do futuro e dos horizontes, sobe o curso do tempo, vai do presente ao passado, nunca do passado ao presente. Mas essas verdades ético-ontológicas precisam ser desveladas de modo lento: primeiro é preciso enganar-se, acreditar-se mandatário, confundir objetivo com razão na unidade do amor materno, viver uma alegre alienação e depois consumir em si mesmo essa falsa alegria, deixar as infiltrações estrangeiras se dissolverem no movimento da negatividade, do projeto e da práxis, substituir a alienação pela angústia; estes atos são indispensáveis: isso é o que eu chamaria, aliás, de necessidade da liberdade" (SARTRE, 2013, p. 141 e 142, negrito meu).
} 
isso que, por exemplo, a angústia não é apreendida numa universalidade, nem deve sê-lo. Aludindo à Jean Wahl, Sartre mostra que o conceito de angústia é, antes de tudo, uma "provocação" (SARTRE, 1972, p. 183). Eis a têmpera que ela encontra nesse tipo de pensamento que não privilegia o universal: "pois a angústia para Kierkegaard, não pode em nenhum caso ser objeto de conceito e, de certo modo, na medida em que ela é a fonte de uma livre opção temporalizante da finitude, ela é fundamento não conceitual de todos os conceitos" (SARTRE, 1972, p. 183).

Ora, o que é uma filosofia que toma o conceito como temporalizado em detrimento da sua determinação universal senão uma "nova concepção de pensamento" (SARTRE, 1972, p. 169, negrito meu)? E que é também uma nova forma de construir e usar a linguagem: "Kierkegaard constrói a linguagem de modo a apresentar, no falso saber, as linhas de força que, no pseudoobjeto constituído, dão possibilidades de retornar ao sujeito" (SARTRE, 1972, p. 183). No fundo, tal como em Genet (SARTRE, 2002b, p. 418), seus escritos são armadilhas. Lá onde se espera a verdade objetiva se é remetido a si mesmo, cuja verdade subjetiva nos entrega à nossa própria sorte, posto que, não podendo nos dar a nossa singularidade, apela à radicalização da mesma ao colocá-la em questão. Assim, sua obra escrita é uma "autodestruição da linguagem" (SARTRE, 1972, p. 182):

E é verdade que a morte se apresenta a princípio como uma queda do sujeito no objetivo absoluto. Mas Kierkegaard, em seus escritos - agora inertes ou vivos em nossas vidas propõe o uso inverso das palavras; ele quer uma regressão dialética do significado e das significações ao significante. Ele se apresenta a si mesmo como significante e nos reenvia de volta à nossa trans-historicidade de significantes (SARTRE, 1972, p. 164, 165).

Daí a radicalidade que a singularidade aponta enquanto finitude. A objetividade não reenvia ao absoluto de essência, à totalidade fechada, à História circunscrita e definida, enquanto busca restituir ou fundamentar um solo metafisico e moral para a vida humana. Pelo contrário, aqui o sentido é a própria expressão dessa singularidade e reenvia à finitude do termo, portanto, à liberdade, que não é outra que a nossa própria liberdade. Assim sendo, toda essa estratégia de restituição é um caminho à liberdade concreta, eis a grandeza que a obra apresenta. $O$ privilégio que Sartre dá a Kierkegaard em sua análise é pela expressão mais manifesta que sua obra traz ao não diluir a si mesmo no universal, nem exigir a nossa própria diluição nele, mas assegurar a tomada do singular pelo singular: "É a interiorização desse desamparo e termina na livre realização do único possível de Adão desamparado: a eleição do finito. Nesse instante do pecado há uma restituição do ser original como sentido (SARTRE, 1972, p. 176 e 177). A liberdade como sentido do ser só pode reenviar à nossa própria singularidade, e por isso ela não se deixa institucionalizar, não ao menos enquanto subjetividade. Aqui a subjetividade é absoluta e se dá a compreender, isto é, apela a nós mesmo em nossa própria criação e singularidade. Deste modo, a morte abole a vida subjetiva, mas não modifica o subjetivo (SARTRE, 1972, p. 185) porque o sentido é o universal singular:

\footnotetext{
O sentido é o universal singular: por seu $e u$, que é assunção e superação prática do ser tal como é, o homem restitui ao universo a unidade do envolvimento, gravando-a, como determinação finita e como hipoteca sobre a História futura no ser que a envolve. Adão se temporaliza pelo pecado, livre eleição necessária e transformação radical do que ele é: adão faz entrar no universo a temporalização humana. Isto significa claramente que a liberdade em cada homem é o fundamento da história (SARTRE, 1972, p. 178 e 179).
}

A escolha de si não é a realização ou fundamentação do ser. Para usar a imagem de Adão, ela é assunção do pecado, é contra o ser. A liberdade como fundamento da história mostra que a 
ontologia, per se, não restitui o real sabor da liberdade, mas exige sua tomada histórica e singular, por isso ela exige a dialética e a psicanálise existencial. Eis o sentido da antropologia existencial de Sartre, para a qual uma elucidação da finitude deveria não apenas confluir a toda análise de situação e totalização histórica, mas expressar esse sabor qualitativo, pois é nele que encontramos a real finitude do finito. Assim, o sentido é a razão ontológica do universal singular. Porque, no fundo, o que todo processo institui enquanto existência que é maneira de ser é esse gosto, essa diferença irrompida pela liberdade, a qual nos atinge em nossa subjetividade, a qual se institucionaliza como momento da história, e a qual permanece trans-histórica pela sua irredutibilidade, porquanto "o homem é o ser que transforma seu ser em sentido, o ser pelo qual o sentido vem ao mundo. O sentido é o universal singular" (SARTRE, 1972, p. 179). Assim, a história é dialética, mas o motor próprio é a subjetividade por ser a única condição de alteração de sentido enquanto eleição da finitude:

Pois todos nós somos Adão, na medida em que cada um de nós comete, para si mesmo e para todos, um pecado singular, isto é, que a finitude é para cada um necessária e incomparável. Por sua ação finita o agente desvia o curso das coisas, porém o faz de acordo com o que esse mesmo curso deve ser. O homem é, com efeito, mediação entre a transcendência detrás e a transcendência da frente, e esta dupla transcendência é uma só. Assim, pode dizer-se que, pelo homem, o curso mesmo das coisas se desvia em sua própria deflexão (SARTRE, 1972, p. 179).

Deste modo, a subjetividade não se reduz a sua tomada objetiva na História, e com isso possibilita sua apreensão mesmo depois que uma vida deixou de viver. É nesse sentido que Sartre afirma a tese da contemporaneidade (SARTRE, 1972, p. 185) e da relação entre subjetividades para além do presente vivo. Por isso Sartre enfatiza em seus principais textos essa diferença entre conhecimento e compreensão: "Resumindo, os contemporâneos se compreendem sem se conhecerem; o historiador futuro os conhecerá, mas sua mais difícil tarefa - confinada à impossibilidade -, será compreender como eles se compreendiam" (SARTRE, 1972, p. 172), pois a compreensão sendo legitimada pelas singularidades, apela à diferença. Em outras palavras, compreender uma subjetividade é pôr em questão a minha, é me diferir na sua condição de diferença trans-histórica. A relação entre singularidades é uma relação diferenciadora, e só aqui que a subjetividade é resguardada na sua trans-historicidade sem deixar de remeter a seu tempo na História, e cuja base e condição é a finitude. Conhecemos o passado, mas não nos conhecemos, todavia nos compreendemos porque somos compreensão de si; o historiador futuro nos conhecerá, mas não nos compreenderá, não ao menos da mesma forma que toma conhecimento de nós, pois para isso seria preciso uma outra relação, uma relação na qual ele coloca seu próprio ser em questão. Mas, uma vez que somos todos contemporâneos, a tarefa da antropologia existencial será restituir essa qualidade singular expressa por uma subjetividade, mas só poderá fazê-lo, na tarefa de compreender a si mesmo na História.

Dito de outro modo, é na busca e compreensão de mim mesmo, portanto, em minha liberdade e criação de mim, em que o outro aparece como horizonte também de questão, liberdade e criação, que o compreendo. Mas o ato de compreendê-lo a partir da minha compreensão não faz tal ato uma apreensão objetivante, pois justamente como tal compreensão apela a uma questão em meu ser, tal compressão se insere em minha singularidade tal como me compreendo, e não na tomada inerte de um saber objetivo. Não se trata de imitar Kierkegaard, fazer como ele, pensar o que ele pensou, citá-lo, etc. Mas sim de sentir esse como, esse teor que me leva a um novo giro na questão em meu ser. É minha angústia que se coloca em questão frente aos movimentos de Kierkeggard e se restitui com um teor que não é mais o mesmo de antes, mas que nem por isso é uma cópia de Kierkegaard. Assim, somos contemporâneos dessas subjetividades que insistem 
sobre nosso tempo ao nos dar o gosto da sua liberdade. Kierkegaard, "por sua obra dá a compreender a sua vida. Em 1964 nós a encontramos, na História, feita como uma chamada à compreensão" (SARTRE, 1972, p. 185).

Ora, compreender sua vida, para um ser que é sempre criação de si, só pode ser uma forma de adentrar e singularizar essa criação, criação esta que passa a ser o meio sua própria singularização: “compreender Adão é tornar-se Adão" (SARTRE, 1972, p. 186). Mas, como é impossível para um ser que é irredutível tornar-se outro, a compreensão do outro é, ao pôr em questão a nossa própria liberdade, uma retomada dessa questão por nós mesmos, sendo o outro, então, um convite à compreensão de nós mesmo (SARTRE, 1972, p. 186). A compreensão é a tomada do processo por mim mesmo, sem destituir a minha liberdade ou a do outro, sem confinála à opacidade do em-si ou torná-la regra instituída e estática. Nesse sentido, "a compreensão refere-se sempre a um processo, e é a antítese do saber absoluto" (SILVA, 2003, p. 57). Por isso, para a compreensão, trata-se de assumir que há não uma apreensão de uma forma, de um universal, mas um recomeço que exige que, pela compreensão, eu recomece sempre pelo movimento de minha própria temporalização (SARTRE, 1972, p. 186), e com isso o recomeçamos por outras condições históricas (SARTRE, 1972, p. 187). Deste modo, a compreensão não apreende o outro como transcendência, pelo contrário, ela pressupõe uma "relação de interioridade e imanência recíprocas" (SARTRE, 1972, p. 188) entre essas singularidades. Daí que a compreensão da História não seja a elevação do singular ao universal, mas a comunicação e passagem de um singular ao outro, de modo que Kierkegaard aparece tanto na sua irredutibilidade quanto na irredutibilidade daquele que o toma por sua própria singularidade. Isto é não apenas o que encontramos que Kierkegaard dá a compreender, mas o que Sartre, a partir de Kierkegaard, mas por sua singularidade, dá a compreender. Aqui temos Kierkegaard, mas também Sartre, e uma relação singular entre esses singulares, pois no limite, só há relações entre singulares, e o universal e a época não são senão essa relação instituída ou estagnada no prático-inerte como solo desse ultrapassamento que é a singularidade. Destarte, "Kierkegaard vive porque, recusando o saber, ele revela a contemporaneidade trans-histórica dos mortos e dos vivos" (SARTRE, 1972, p. 188). Essa condição de contemporaneidade histórica institui que "as palavras de Kierkegaard são nossas palavras" (SARTRE, 1972, p. 187), porém tão somente à medida que suas palavras não remetem somente a Kierkegaard vivo, mas a mim mesmo:

Assim, Kierkegaard está vivo se a nós nos é possível chegar a ser Kierkegaard, ou se, inversamente, este morto não cessa de fazer se instituir pelos vivos, tomando suas vidas emprestadas, introduzindo-se nelas e alimentando sua singularidade com a nossa. Ou, em outras palavras: Kierkegaard está vivo se aparece no coração do saber como o denunciador perpétuo, em cada um, do não-saber, do recôncavo dialético em que a interiorização se transforma em exteriorização, em uma palavra, da existência (SARTRE, 1972, p. 186).

Assim sendo, a vida de Kierkegaard pode desaparecer com sua morte, mas não o próprio Kierkegaard. Ele é restituído como sentido e reinventado segundo a eleição mesma de minha finitude. Trata-se de me descobrir e redescobrir Kierkegaard na ironia, no humor, na angústia, mas na minha angústia5: "Kierkegaard é restituído como minha aventura, não em seu sentido único, senão ao nível de seu ser-aventureiro, na medida em que eu tenho que ser o acontecimento que me advém desde fora" (SARTRE, 1972, p. 187). Sartre pensa essa restituição dentro da esfera

\footnotetext{
5 “Todo pecado é particular enquanto institui, em condições particulares, uma pessoa única; e é, por sua vez, o pecado enquanto é eleição da finitude e desafio blasfemo a Deus. Assim, a universalidade do pecado está contida na singularidade da opção. Por ela todo homem chega a ser sempre todo homem. Cada um faz avançar a história voltando a iniciá-la, e também sendo de antemão, em si mesmo, as reinicializações futuras" (SARTRE, 1972, p. 186 e 187).
} 
da imanência, do sentido, como relação de interioridade porque cada um se manifesta sempre como um "absoluto incomparável" (SARTRE, 1972, p. 188), cuja relação é sempre focada no indivíduo vivente, na vivência, na medida em que por ela "eu o recomeço em circunstâncias históricas distintas" (SARTRE, 1972, p. 188). Recomeço sua angústia e sua ironia, me faço por ela, mas a faço diferente pelo simples fato de que a vivo. É nesse sentido que Sartre pensa a multiplicidade do sujeito. De fato, tanto Kierkegaard como Sartre são sujeitos únicos pelo fato de que são indivíduos singulares, mas uma vez morto, Kierkegaard "não ressuscita inteiramente senão que se converte em sujeito múltiplo, isto é, união interna de nossas singularidades. Cada um de nós é Soeren como aventura (SARTRE, 1972, 188, negrito meu). Mas somos também múltiplos por sermos Kierkegaard nos fazendo a nós mesmo, e tantos outros. A singularidade pressupõe essa multiplicidade de fundo ao mesmo tempo que permite sua retomada e reinvenção múltipla. Toda a sua composição é o próprio processo de singularização. E, assim, na finitude do humano encontramos a infinitude da liberdade:

Kierkegaard vive porque ao rechaçar o saber, revela a contemporaneidade trans-histórica dos mortos e dos vivos, isto é, manifesta que todo homem é todo o homem enquanto universal singular. Ou, se se prefere, pelo fato de que, contra Hegel, ele manifesta a temporalização como dimensão trans-histórica da História, a humanidade perde seus mortos e os recomeça absolutamente mediante seus vivos (SARTRE, 1972, p. 188.).

Portanto, é como trans-histórico que o homem é compreendido como universal singular. A finitude de Kierkegaard não é sua vivência, mas o modo como ele vive. Esse modo, sua "profundidade negativa" (SARTRE, 1972, p. 188) que é a aventura individual implica essa qualidade singular como sentido do ser. Se somos seu contemporâneo é porque a relação que temos com ele é existencial. Ser trans-histórico, nesse sentido, é resguardar a existência ante a História impedindo-a que ela converta o indivíduo em mero saber histórico, mantendo a relação não na linearidade da narrativa histórica, mas como "ambivalências vividas" (SARTRE, 1972, p. 189). Sujeito múltiplo, trans-histórico, irredutível ao saber objetivo, uma liberdade sempre contemporânea, eis não apenas Kierkegaard, mas todo aquele que o compreende para compreender a si mesmo. Realizamos, assim, como ele, "o esforço vivo para escapar ao saber pela vida reflexiva, sua pretensão de ser, na sua singularidade, no coração da sua finitude, o absolutosujeito" (SARTRE, 1972, p. 153).

Ora, o que é uma filosofia que, tal como alude a Kierkegaard uma nova forma de pensar, aponta à singularidade e a sua compreensão? Uma filosofia que não faz da liberdade um conhecimento, mas uma compreensão; que não faz da liberdade uma forma, mas uma vida; que não faz da liberdade o atributo de um sujeito, mas sua qualidade fundamental como escolha e gosto de ser; que faz da liberdade não um desenvolvimento da História, mas sua constituição trans-histórica; que faz da liberdade não uma identidade, mas uma singularidade composta de uma multiplicidade; que faz da liberdade não o Ser, mas a finitude: eis a filosofia de Sartre. Ademais, a totalização histórica enquanto alicerçada pelas subjetividades faz da História não o desenrolar do Ser, pois "a totalização não leva a uma totalidade, e sim a contraposições inesgotáveis, e são estas que resguardam a totalização em sua finitude" (BORNHEIM, 1983, p. 316, negrito meu). Essa dialética do singular ao singular aponta a finitude como diferença e faz da contraposição dessas diferenças a própria instauração da finitude:

Se reduzíssemos todo o processo totalizador a um todo contínuo e homogêneo ele ficaria descaracterizado, tornando-se algo indistinto. O processo é essencial não simplesmente enquanto processo, mas enquanto alcança uma determinada totalização, e assim estabelecem-se as diferenças no real, as distinções, as individualizações. Ou por outra: pela totalização que chega a ser tal, é que a realidade se torna propriamente finita, porquanto 
sem esse chegar a ser tal tudo não passaria de um simples contínuo indiferenciado. Assim, as diferenças só são pelas contraposições, e a diferença contraposta é que instaura a finitude (BORNHEIM, 1983, p. 315, negrito meu).

No limite, não há conhecimento da liberdade, mas apenas compreensão de uma liberdade. Por isso que o empreendimento biográfico deve não apenas descrever a narrativa da vida de um homem, mas por ela, ou por outras formas, transmitir, comunicar, "um certo sabor qualitativo" (BORNHEIM, 1998, p. 43). Isto é, ele deve dar a compreender uma liberdade. Nenhuma imagem moralizante e metafisica da liberdade cabe aqui. É, antes, tal como Kierkegaard, mas também diferente dele, o sentimento de vazio que a obra de Sartre deixa. Ela afere a liberdade como sendo a própria angústia, mas também como criação de si, na medida em que ela convida sem coagir, aponta sem determinar, trai sem ter prometido nada: eis como Sartre dá a compreender a liberdade ao seu leitor. Daí a frustração que se possa ter ao não encontrar na obra de Sartre a tão sonhada fórmula da liberdade, mas apenas o fracasso de si mesmo. É o jogo do perde-ganha, o jogo da liberdade em Sartre. Tal como Genet, Sartre ri de seus leitores. Mas esse riso, também ele, é um convite à liberdade. Ademais, quem acreditaria numa liberdade séria, instituída numa obra, objetivada em uma filosofia? A liberdade em Sartre não é um conhecimento, mas um convite à nossa própria compreensão, à nossa singularização. Em seu emblemático riso, a liberdade é generosidade, doação de ser. Diante disso a tarefa do filósofo se volta a uma espécie de ontologia prática, na medida em que elucidar a finitude do finito envolve a determinação da qualidade fundamental cujo invólucro é o indivíduo singular e concreto, para a qual esta singularidade é o próprio sentido do Ser como finitude. Tudo se passa como se o filósofo se tornasse um antropólogo existencial, para não dizer um psicanalista existencial. Somos levados, portanto, da imagem singular do finito à consideração da nossa própria finitude, nosso tempo, nossa liberdade. 


\section{Referências}

BORNHEIM, Gérd Alberto. O Idiota e o Espírito Objetivo. Rio de Janeiro: UAPÊ e SEAF, 1998. BORNHEIM, Gérd Alberto. Dialética: teoria e práxis - ensaio para uma crítica da fundamentação ontológica da Dialética. 2. ed. Porto Alegre: Globo, 1983.

SARTRE, Jean-Paul. Crítica da Razão Dialética - Tomo I: Teoria dos conjuntos práticos, precedido por Questão de método. Tradução: Guilherme João de Freitas Teixeira. Rio de Janeiro: DP\&A, 2002a.

SARTRE, Jean-Paul. Cahiers por une morale. France: Gallimard, 1983.

SARTRE, Jean-Paul. L'être et le néant-Essai d'ontologie phénoménologuique. France: Gallimard, 2007.

SARTRE, Jean-Paul. Saint Genet - ator e mártir. Petrópolis, RJ: Vozes, $2002 \mathrm{~b}$.

SARTRE, Jean-Paul. L' Universel Singulier. In. Situations IX. Gallimard, Paris, 1972.

SARTRE, Jean-Paul. O Idiota da Família - Gustave Flaubert de 1821 a 1857. Vol. 1. Porto Alegre, RS: L\&PM, 2013.

SILVA, Franklin Leopoldo e. Conhecimento e identidade histórica em Sartre. Trans/form/Ação, São Paulo, 26(2): 43-64, 2003.

Autor(a) para correspondência / Corresponding author: Marcelo Prates.fmarceloprates1@gmail.com 